\title{
A Study of Effectiveness of Midblock Pedestrian Crossings: Analyzing a Selection of High-Visibility Warning Signs
}

Rebekka Apardian

Bhuiyan Monwar Alam

Associate Professor, Department of Geography \& Planning, The University of Toledo,

\begin{abstract}
The purpose of this paper is to examine a selection of different high-visibility pedestrian warning signs at midblock crossings and summarize the most effective options, where effectiveness is measured by pedestrian safety. Four locations are observed. Effectiveness is measured by the vehicle yield percentage, the pedestrian conflicts, and pedestrian wait time. The findings largely concur with previous literature, concluding that speed and road width are important factors in determining a driver's likeliness to yield. This paper also hypothesizes that signage on both sides of the roadway and overhead signage also makes a positive visibility impact.
\end{abstract}

Keywords: pedestrian safety, midblock crosswalk, behavior, yield rate, high-visibility, warning signs 
A Study of Effectiveness of Midblock Pedestrian Crossings

Apardian, R. and Alam, B. M.

Interdisciplinary Journal of Signage and Wayfinding; Volume 1; Issue 2

\section{Introduction}

Pedestrian safety must be a top priority within the transportation planning community as cities promote sustainable transportation, alternative travel modes, and healthy lifestyles. In order to maximize safety, all available options and methods must be analyzed and compared. In the case of a pedestrian street crossing, it is important to strategically install midblock pedestrian crossings at locations pedestrians may decide to jaywalk. These midblock crossings occur between intersections where a pedestrian would find it convenient to cross in the middle of the street rather than walk to the nearest intersection. This location presents an additional challenge for vehicle-pedestrian conflict that must be assessed. A driver is, in most cases, more used to looking for a crossing pedestrian at an intersection that at a midblock location. Vehicles may be moving at a quicker speed through midblock pedestrian crossings than through crossings at intersections where a driver may be either coming to a stop or starting to move after being stopped. This necessitates effective methods for ensuring a safe crossing and increased driver awareness at a mid-block crossing.

This paper examines pedestrian awareness/warning methods and their effectiveness at midblock crossings. These pedestrian awareness/warning methods often tend to be signs or signals, and can be either of a passive nature or of an active nature. A passive method is one that is static and does not change. Examples of this would be physical infrastructure, such as a raised crosswalk or fixed signage. An active method is dynamic and responds to its environment in order to facilitate safer crossing. For example, a pedestrian-actuated signal that stops traffic with a light when pushed would be considered an active method. The pedestrian awareness/warning methods studied specifically here include signals, signs, and pavement markings.

\section{Literature Review}

In general, it has been found that higher speeds and wider roadways result in increased 
A Study of Effectiveness of Midblock Pedestrian Crossings

Apardian, R. and Alam, B. M.

Interdisciplinary Journal of Signage and Wayfinding; Volume 1; Issue 2

pedestrian risk at a midblock crossing. A report by the National Cooperative Highway Research Program (NCHRP) noted that motorists are less likely to yield at a high speed and high vehicle volume crossing because they feel inconvenienced and as if the road is for the car, not the pedestrian, under these conditions. NCHRP further suggests that, due to the design of the roadway, motorists often feel as though yielding to a pedestrian is a courtesy rather than the law.

Studies done by the NCHRP found that motorist yielding rate at in-street "yield to pedestrian" signs was relatively high, ranging from $82-91 \%$. These studies were done on all two-lane roads with slow speed limits (25-30 MPH). Huang, Zegeer, and Nassi also found that in-street signs that communicated the law requiring motorists to yield for pedestrians had a high yield rate. The signs in this study were also on low speed roads.

The literature concludes that there are higher yield rates for high-visibility signs, such as diamond-shaped signs with a black pedestrian graphic. For these, the NCHRP found that roads with a speed limit of $25 \mathrm{MPH}$ saw an average motorist yielding rate of $61 \%$. On $35 \mathrm{MPH}$ roads, high-visibility signs saw an average yielding rate that dropped to $17 \%$. This would suggest that speed is a very high indicator of motorist yielding.

Van Houten et. al. (1992) found that the introduction of a reflective sign reading, "stop here for pedestrians" with an arrow pointing towards the desired stopping point resulted in a decrease of pedestrian-vehicle conflicts by $50 \%$ at two different locations. A study by Palamarthy et al., 1994, found that group interactions were significant when determining an appropriate gap for crossing, suggesting safety increases with higher numbers of pedestrians.

\section{Method}

In order to study the effectiveness of passive signs for midblock crossings, four different studies were conducted. Each of these observations were done in fifteen-minute intervals. The data 
A Study of Effectiveness of Midblock Pedestrian Crossings

Apardian, R. and Alam, B. M.

Interdisciplinary Journal of Signage and Wayfinding; Volume 1; Issue 2

recorded for the signs include number of pedestrians per crossing group, the type of eventual crossing (allowed by a yielded vehicle, a gap in traffic occurred, or the pedestrian forced a vehicle to yield to them by crossing into traffic), and the number of vehicles that passed before a crossing was achieved by a waiting pedestrian. The crossing observations were categorized by the type of crossing that occurred when the pedestrian first entered the crosswalk. A near conflict is categorized by a near vehicle-pedestrian contact, as has been described in past research on conflict analysis (Palamarthy et. al). This can be in the form of a pedestrian jumping out of the way, a vehicle braking suddenly, swerving, or speeding in close proximity of a crossing pedestrian. The overall yield rate for each location was calculated by counting the number of vehicles who passed a waiting pedestrian (had the opportunity to yield) and the number of vehicles who actually yielded for the pedestrian. Forced yields are not included.

\section{Observations}

\section{High Street Midblock Crossings}

The first two studies were observations of midblock crossings on High Street in Columbus, Ohio. They are across from Ohio State University and lead from the university into retail, restaurants, and residential mixed land uses. There are four lanes of traffic (two in each direction) plus one turning lane. The far right lanes have "sharrows" (indicating that motorists should share the lane with bicycles) as painted markings in the middle of the lane and the posted speed limit is 25 MPH, though observations showed that most motorists drive 30-35 MPH through this area. The majority of pedestrians are students.

\section{High-Visibility Signage on High Street at 18th Avenue}

The first location, south of Woodruff Avenue and at about 18th Avenue, is shown in Map 1. This crossing has a diamond shaped pedestrian high-visibility sign side-mounted at the crosswalk, as shown in Figure 1. There is a "yield to pedestrians here" sign further upstream, pointing to a thick white line. The crosswalk is striped and visible. There is a row of triangles leading up to the 
A Study of Effectiveness of Midblock Pedestrian Crossings

Apardian, R. and Alam, B. M.

Interdisciplinary Journal of Signage and Wayfinding; Volume 1; Issue 2

crosswalk as well. These signs and pavement markings exist in both directions of travel.

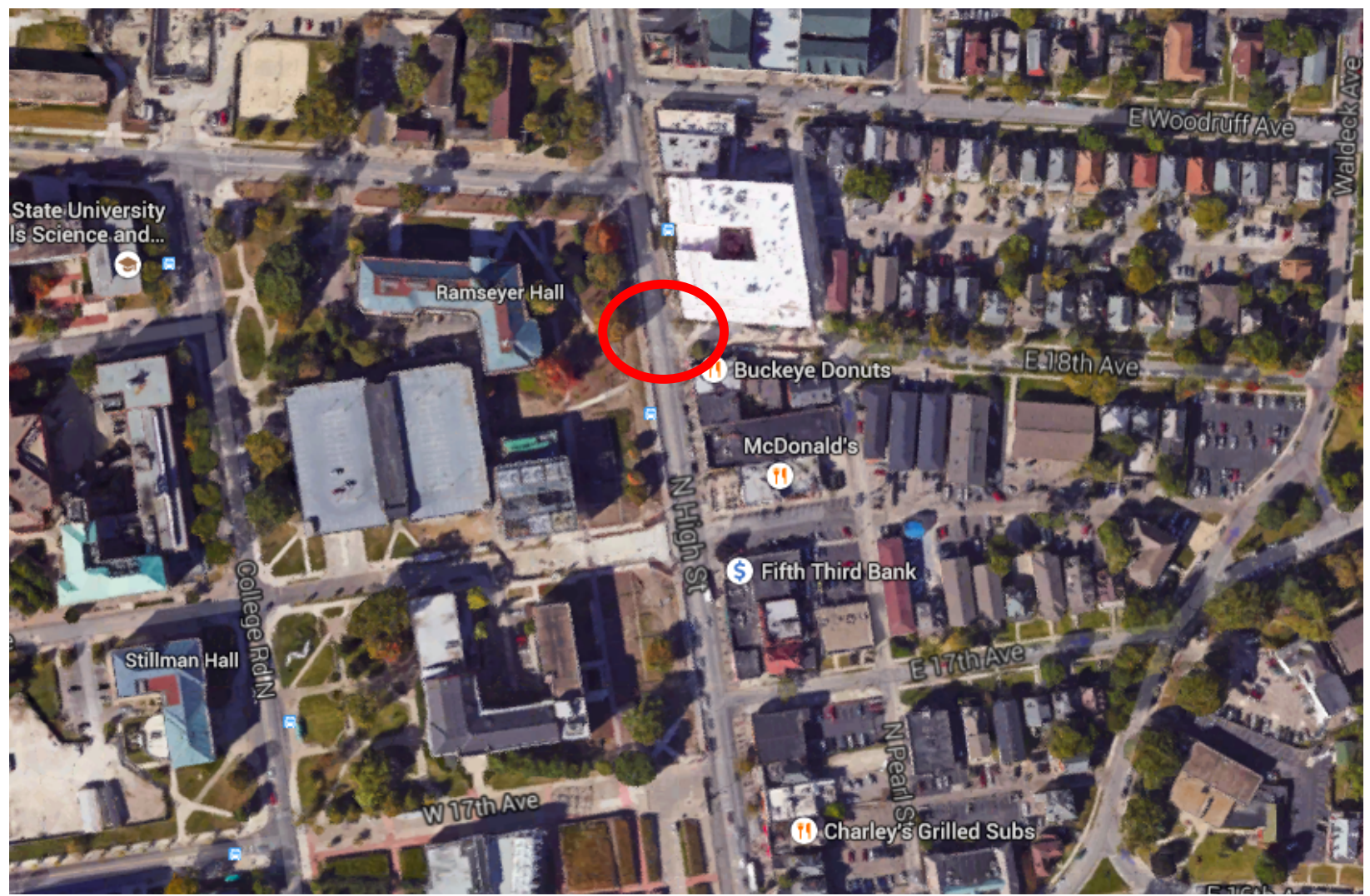

Map 1: High Street, at about 18th Avenue across from Ohio State (Google Maps) 
A Study of Effectiveness of Midblock Pedestrian Crossings Apardian, R. and Alam, B. M.

Interdisciplinary Journal of Signage and Wayfinding; Volume 1; Issue 2

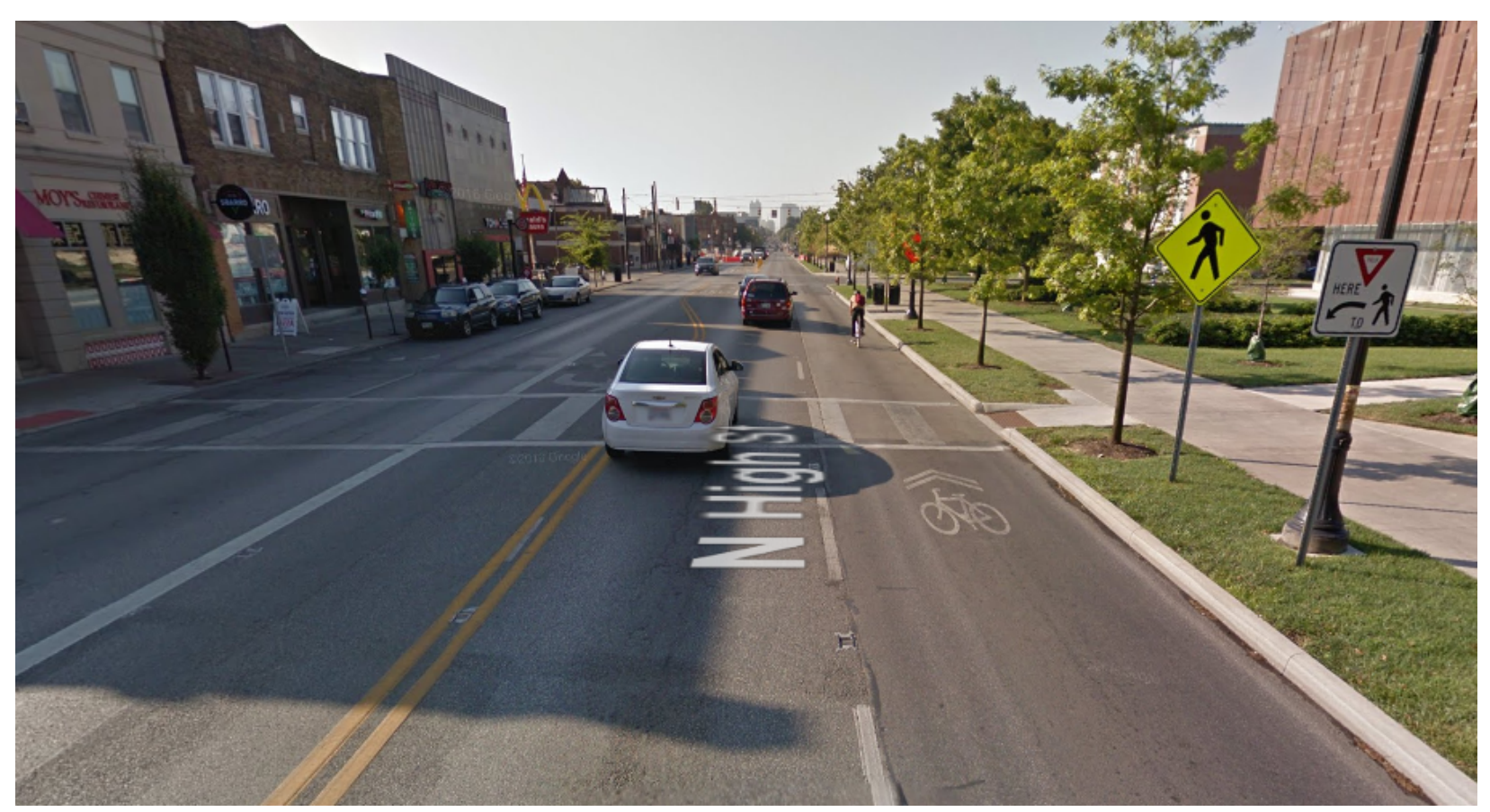

Figure 1: Crossing conditions on High Street south of Woodruff Avenue, at about 18th Avenue (Google Maps)

Table 1 shows the observations from this crossing. These observations revealed a low vehicle yield rate, similar to that of which the literature found with these standard signs. There were 14 crossing groups, totaling 24 pedestrians. The summary of the crossing data for this location are shown in Table 2. Of those crossing groups, eight (57.14\%) made their eventual cross during a gap in traffic. Two (14.29\%) were yielded to by a vehicle, and the remaining four $(28.57 \%)$ crossed by stepping into the roadway and forcing traffic to yield to them. One near conflict occurred during a crossing, which happened at the opposite end from where the pedestrian began his crossing. 
A Study of Effectiveness of Midblock Pedestrian Crossings Apardian, R. and Alam, B. M.

Interdisciplinary Journal of Signage and Wayfinding; Volume 1; Issue 2

Table 1

\section{Data from High-Visibility Signage Midblock Crossing Location \#1}

Location: High Street, across from Ohio State University, south of W Woodruff Avenue, at about $\mathrm{E}$ 18th Avenue

Design: Striped, (The following in each direction): Row of triangles painted on roadway approaching crosswalk, Diamond-shaped neon pedestrian sign, "Yield here to pedestrian" square sign

Street: 4 lanes plus turning lane, north and south travel, $25 \mathrm{MPH}$, "sharrows" in one lane each direction

\begin{tabular}{|c|c|c|c|c|}
\hline & $\begin{array}{l}\text { Number Pedestrians } \\
\text { Per Crossing }\end{array}$ & $\begin{array}{c}\text { Type of } \\
\text { Eventual Crossing }\end{array}$ & $\begin{array}{c}\text { Number } \\
\text { Vehicles Passed } \\
\text { Before Crossing }\end{array}$ & Near Conflict \\
\hline & 5 & gap & 5 & \\
\hline & 1 & gap & 1 & \\
\hline & 1 & forced & 1 & \\
\hline & 2 & gap & 0 & \\
\hline & 1 & gap & 3 & \\
\hline & 1 & gap & 0 & \\
\hline & 1 & gap & 0 & \\
\hline & 2 & forced & 1 & \\
\hline & 1 & gap & 0 & \\
\hline & 1 & forced & 1 & 1 \\
\hline & 1 & forced & 2 & \\
\hline & 2 & yield & 1 & \\
\hline & 2 & gap & 0 & \\
\hline & 3 & yield & 7 & \\
\hline Total & 24 & & 22 & \\
\hline
\end{tabular}


A Study of Effectiveness of Midblock Pedestrian Crossings Apardian, R. and Alam, B. M.

Interdisciplinary Journal of Signage and Wayfinding; Volume 1; Issue 2

Table 2

$\underline{\text { Summary of High-Visibility Signage Midblock Crossing Location \#1 }}$

\begin{tabular}{|l|c|r|}
\hline \multicolumn{3}{|l|}{ Number of Pedestrians That Crossed: } \\
\hline During Gap & 14 & $58.33 \%$ \\
\hline During Yield & 5 & $20.83 \%$ \\
\hline Forced Yield & 5 & $20.83 \%$ \\
\hline
\end{tabular}

Number of Pedestrian Groups That Crossed:

\begin{tabular}{|l|c|r|}
\hline During Gap & 8 & $57.14 \%$ \\
\hline During Yield & 2 & $14.29 \%$ \\
\hline Forced Yield & 4 & $28.57 \%$ \\
\hline
\end{tabular}

\begin{tabular}{|l|c|}
\hline Vehicles that passed & 22 \\
\hline Vehicles that yielded & 2 \\
\hline Total vehicles & 24 \\
\hline Yield Rate & $\mathbf{8 . 3 3 \%}$ \\
\hline
\end{tabular}

Two groups received yields. One of these two groups watched six vehicles pass while they were standing on the edge of the curb, visibly waiting to cross, before the 7th vehicle finally yielded for them. The other group had to wait for one passing vehicle before the 2 nd vehicle yielded. No groups were yielded to by the first approaching vehicle. The overall yield rate for this location was $8.33 \%$. There were 24 vehicles who had the opportunity to yield and only two did. 
A Study of Effectiveness of Midblock Pedestrian Crossings

Apardian, R. and Alam, B. M.

Interdisciplinary Journal of Signage and Wayfinding; Volume 1; Issue 2

It may be worth noting that the two groups that were yielded to had two and three pedestrians crossing in each group, whereas three of the four groups that forced a yield consisted of only one pedestrian.

The pedestrian groups who crossed during gaps were routinely able to cross without waiting. All but three of the 14 groups crossing during a gap were able to proceed across the street immediately after arriving at the crosswalk. The other three groups $(21.42 \%$ of gap crossing groups) had to wait for traffic to pass them and a gap to appear. This would indicate that traffic is not constant at this location and enough natural gaps occur for a pedestrian to cross on their own. It is important to note that the crossing observations were categorized by the type of crossing that occurred when the pedestrian first entered the crosswalk. This means that, even though a pedestrian crossed during an initial gap in traffic, by the time they reached the other side, they may have forced motorists to yield to them. Overall, qualitatively speaking, motorists seemed patient when forced to yield in this manner. Only a few created potential conflict environments by trying to speed past a crossing pedestrian group before the group could reach the motorist's current travel lane. That is how the one recorded conflict did occur.

\section{High-Visibility Signage on High Street at 14th Avenue}

The second study of a midblock crossing on High Street is located in the same environment, at about 14th Avenue, a few blocks south of the first location (Map 2). This crossing has a diamond shaped pedestrian high-visibility sign side-mounted at the crosswalk, similar to the previous crossing. As shown in Figure 2, however, this sign also has a small rectangular high-visibility sign below the diamond sign with an arrow pointing towards the crosswalk. There is again a "yield to pedestrians here" sign further upstream, pointing to a thick white line. The crosswalk is striped and visible. There is a row of triangles leading up to the crosswalk as well. These signs and pavement markings exist in both directions of travel. 
A Study of Effectiveness of Midblock Pedestrian Crossings

Apardian, R. and Alam, B. M.

Interdisciplinary Journal of Signage and Wayfinding; Volume 1; Issue 2

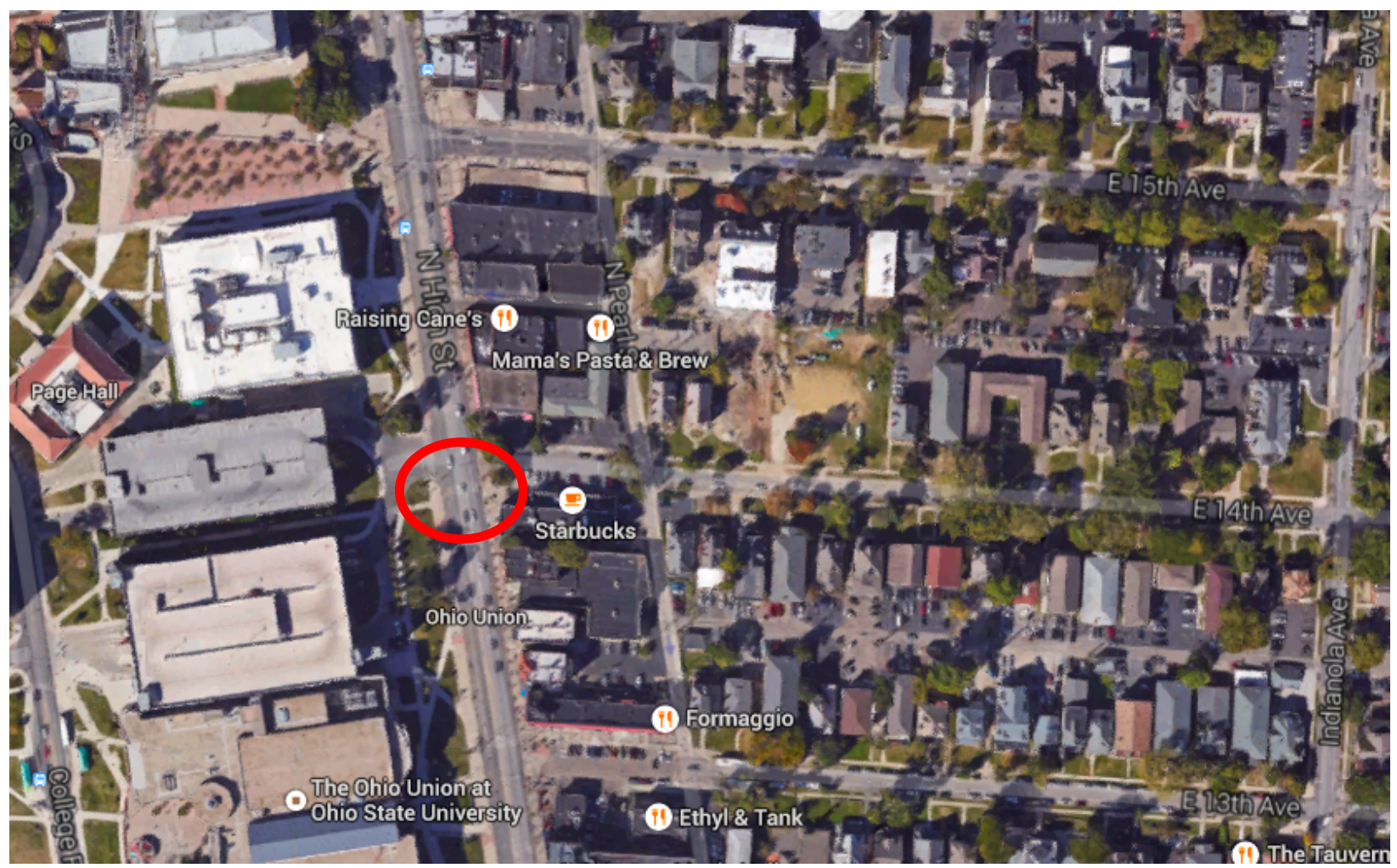

Map 2: High Street, at about 14th Avenue across from Ohio State (Google Maps) 
A Study of Effectiveness of Midblock Pedestrian Crossings Apardian, R. and Alam, B. M.

Interdisciplinary Journal of Signage and Wayfinding; Volume 1; Issue 2

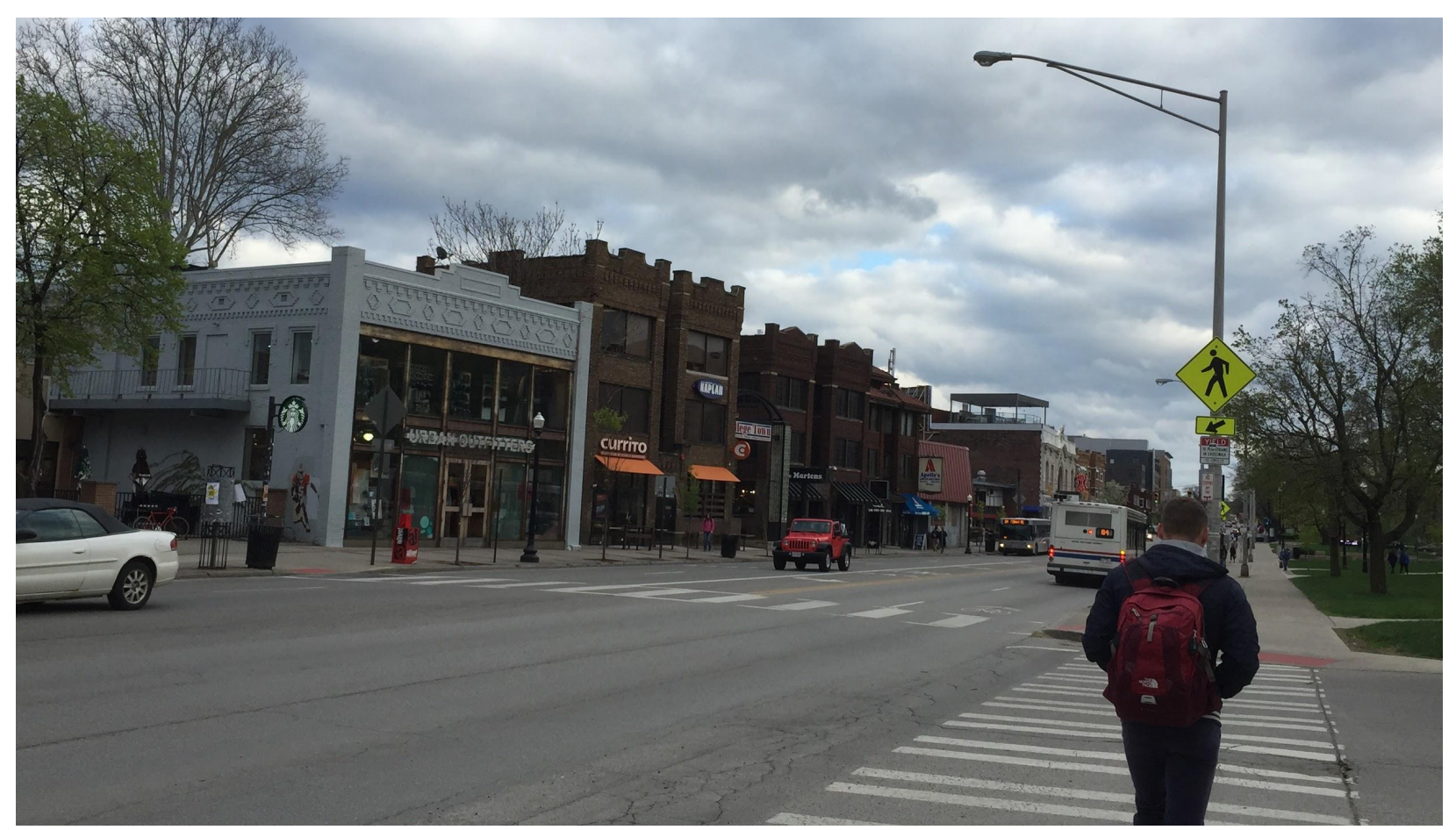

Figure 2: Crossing conditions on High Street south of Woodruff Avenue and at about 14th Avenue

Table 3 shows the observations from this crossing. Here, 33 pedestrian groups were recorded crossing, for a total of 47 pedestrians. The summary of this data is in Table 4. Of these 33 groups, 26 (78.79\%) crossed during a gap, four (12.12\%) received a yielded vehicle, and three $(9.09 \%)$ forced a vehicle to yield to them. 10 (38.46\%) of the 26 gap-crossing groups had to wait for a gap in traffic after arriving at the crosswalk. These waits ranged from one passing vehicle to 16. 
A Study of Effectiveness of Midblock Pedestrian Crossings Apardian, R. and Alam, B. M.

Interdisciplinary Journal of Signage and Wayfinding; Volume 1; Issue 2

Table 3

\section{Data from High-Visibility Signage Midblock Crossing Location \#2}

Location: High Street, across from the Ohio Union parking Garage and Urban Outfitters, at about 14th Avenue

Design: Striped; (The following in each direction): Row of triangles painted on roadway approaching crosswalk, Diamond-shaped neon pedestrian sign with rectangular neon arrow and small square "yield to pedestrians in crosswalk" sign, "yield here to pedestrian" square sign

Street: 4 lanes plus turning lane, north and south travel, $25 \mathrm{MPH}$, "sharrows" in one lane each direction

\begin{tabular}{|c|c|c|c|}
$\begin{array}{c}\text { Number Pedestrians } \\
\text { Per Crossing }\end{array}$ & $\begin{array}{c}\text { Type of } \\
\text { Eventual Crossing }\end{array}$ & $\begin{array}{c}\text { Number Vehicles Passed } \\
\text { Before Crossing }\end{array}$ & $\begin{array}{c}\text { Near } \\
\text { Conflict }\end{array}$ \\
\hline 2 & gap & 0 & \\
\hline 1 & gap & 0 & \\
\hline 2 & gap & 0 & \\
\hline 1 & yield & 0 & \\
\hline 1 & gap & 0 & 1 \\
\hline 1 & gap & 2 & \\
\hline 1 & forced & 1 & \\
\hline 6 & gap & 0 & \\
\hline 2 & gap & 2 & \\
\hline 1 & gap & 0 & \\
\hline 2 & gap & 0 & \\
\hline 1 & forced & 1 & \\
\hline 1 & gap & 0 & \\
\hline 1 & yield & 0 & \\
\hline 1 & forced & 4 & \\
\hline 1 & yield & 0 & \\
\hline
\end{tabular}


A Study of Effectiveness of Midblock Pedestrian Crossings

Apardian, R. and Alam, B. M.

Interdisciplinary Journal of Signage and Wayfinding; Volume 1; Issue 2

\begin{tabular}{|c|c|c|c|c|}
\hline & 1 & gap & 16 & \\
\hline & 2 & gap & 0 & \\
\hline & 1 & gap & 0 & \\
\hline & 1 & gap & 1 & \\
\hline & 2 & yield & 1 & \\
\hline & 1 & gap & 3 & \\
\hline & 1 & gap & 4 & \\
\hline & 2 & yield & 1 & 1 \\
\hline & 1 & gap & 0 & \\
\hline & 2 & gap & 0 & \\
\hline & 2 & gap & 0 & \\
\hline & 1 & gap & 3 & \\
\hline & 1 & gap & 0 & \\
\hline & 1 & gap & 1 & \\
\hline & 1 & gap & 0 & \\
\hline & 1 & gap & 6 & \\
\hline & 1 & gap & 2 & \\
\hline Total & 47 & & 48 & 2 \\
\hline
\end{tabular}


A Study of Effectiveness of Midblock Pedestrian Crossings Apardian, R. and Alam, B. M.

Interdisciplinary Journal of Signage and Wayfinding; Volume 1; Issue 2

Table 4

$\underline{\text { Summary of High-Visibility Signage Midblock Crossing Location \#2 }}$

\begin{tabular}{|l|c|r|}
\hline \multicolumn{3}{|c|}{ Number of Pedestrians That Crossed: } \\
\hline During Gap & 37 & $78.72 \%$ \\
\hline During Yield & 7 & $14.89 \%$ \\
\hline Forced Yield & 3 & $6.38 \%$ \\
\hline & 47 & \\
\hline
\end{tabular}

Number of Pedestrian Groups That Crossed:

\begin{tabular}{|l|c|r|}
\hline During Gap & 26 & $78.79 \%$ \\
\hline During Yield & 4 & $12.12 \%$ \\
\hline Forced Yield & 3 & $9.09 \%$ \\
\hline & 33 & \\
\hline
\end{tabular}

\begin{tabular}{|l|c|}
\hline Vehicles that passed & 48 \\
\hline Vehicles that yielded & 4 \\
\hline Total vehicles & 52 \\
\hline Yield Rate & $\mathbf{7 . 6 9 \%}$ \\
\hline
\end{tabular}


A Study of Effectiveness of Midblock Pedestrian Crossings

Apardian, R. and Alam, B. M.

Interdisciplinary Journal of Signage and Wayfinding; Volume 1; Issue 2

The number of vehicles that passed before a yield occurred (when a yield occurred) were on average much lower than the previous crosswalk on High Street at 18th Avenue. In fact, all four groups had a vehicle yield to them after one or less passing vehicle. This is a quick yield rate for the yields that did occur. The yield groups were small, two or fewer pedestrians each.

Again, the three groups that forced a vehicle to yield to them consisted of only one pedestrian. One of the two near conflicts occurred during one of these forced yields. The other occurred while the pedestrian group was crossing the far two lanes of traffic after being yielded to on their origin side. In this case, a vehicle sped up quickly in front of a group of crossing pedestrians in order to avoid yielding to them.

The overall yield rate for this location was $7.69 \%$. This is found by taking the number of pedestrian groups who were eventually yielded to (four) divided by the number of vehicles who passed a waiting pedestrian group (52).

These crossings do not meet all of the criteria for "effective." There were near conflicts, forced yields, and there did not appear to be a high level of visibility of waiting pedestrians. One hypothesis, in addition to faster speeds and a high number of lanes, is that the pedestrian is not positioned in a high-visibility location when waiting to cross due to the street design. Lane width, lane numbers, street-level crosswalk, and no signage in the street all likely contribute to this.

\section{High-Visibility Signage on Rich Street Between 3rd Street and High Street}

The next sign study at a midblock crossing occurred on Rich Street, in between 3rd Street and High Street in Downtown Columbus, Ohio (Map 3). This crossing is in between Columbus Commons, an outdoor event space, and the associated parking garage. This garage is used during the week for many downtown employees and professionals while the event space is used for a 
A Study of Effectiveness of Midblock Pedestrian Crossings Apardian, R. and Alam, B. M.

Interdisciplinary Journal of Signage and Wayfinding; Volume 1; Issue 2

few hours a week. During the study, the event space was unused and functioned as an open green space. The street consists of three one-way lanes headed west. No posted speed limit was visible. The crosswalk is popularly used for crossing the street and heading into the garage. Signs posted at this location included the following: Diamond-shaped neon pedestrian sign with neon rectangular arrow on each side of street, "yield here to pedestrian" square sign each side of street, overhead diamond-shaped neon pedestrian sign. The crosswalk was striped and a row of triangles leading up to crosswalk was present (Figure 3). An important observation to make here is that, due to the one way nature of the road, both sides of the road displayed the same signs, which results in increased visibility of them by travel lanes.

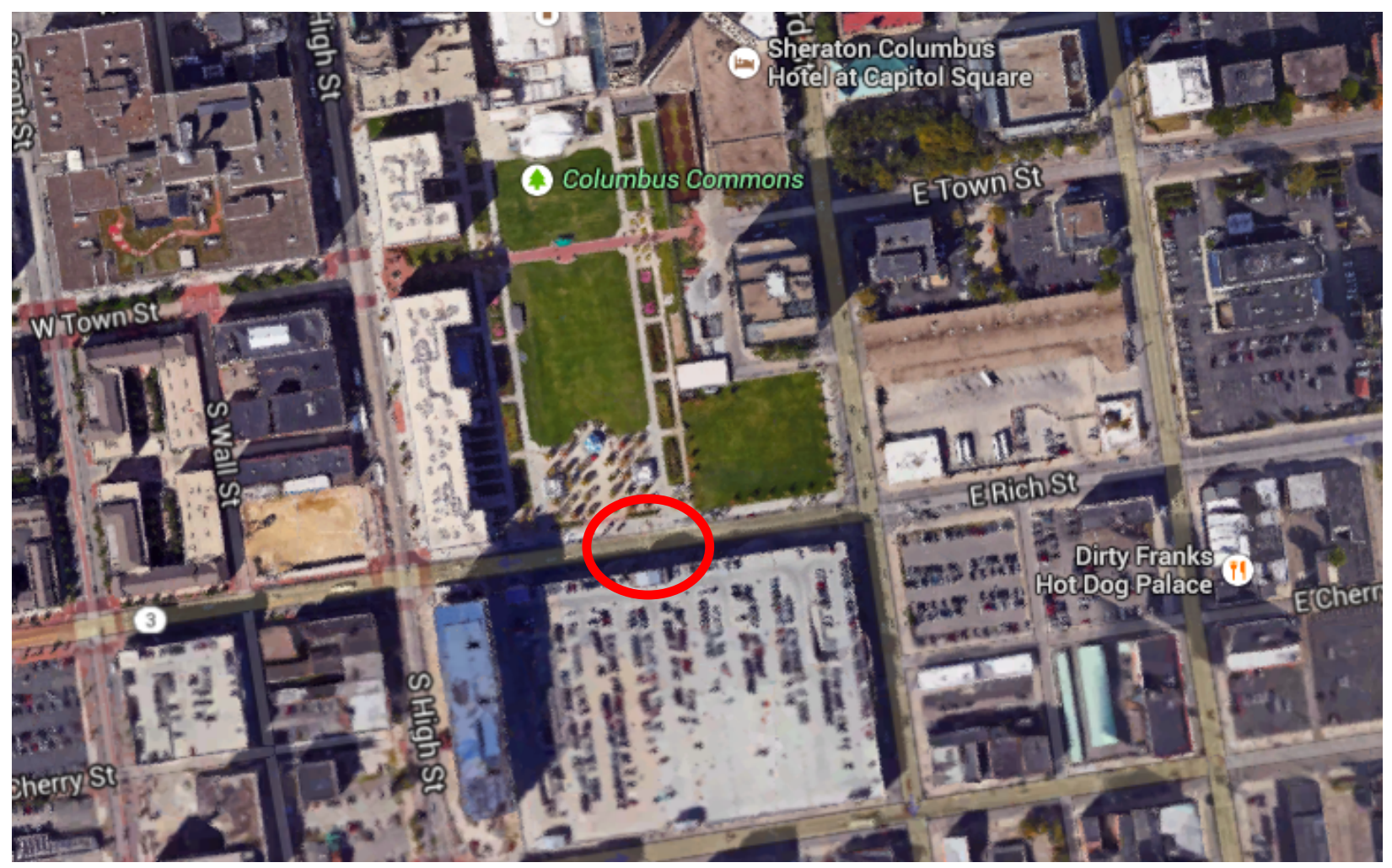

Map 3: Rich Street, in between 3rd Street and High Street in Downtown Columbus, Ohio (Google Maps) 


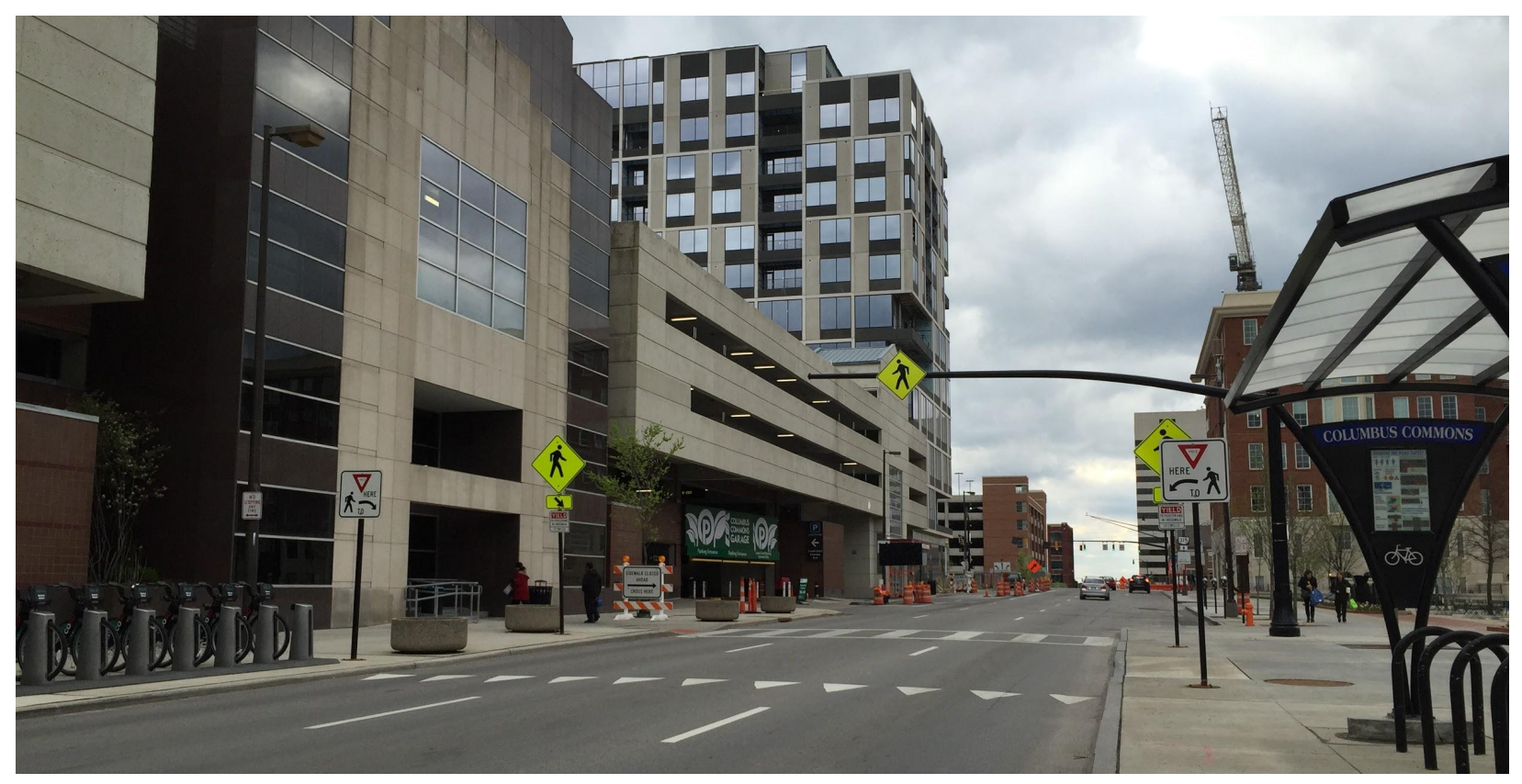

Figure 3: Crossing conditions on Rich Street, in between 3rd Street and High Street in Downtown Columbus, Ohio. The garage can be seen here on the left.

The results of this observation are shown in Table 5. A total of 148 pedestrians crossed here during the observational period, in a total of 62 groups. The majority of pedestrians were observed to be business professionals leaving work for the day. Of the 62 groups, 45 (72.58\%) were yielded to and the remaining $17(27.42 \%)$ crossed during a natural gap in traffic. Table 6 shows these results summarized. There were no forced yields and no near conflicts. Only five $(8.06 \%)$ groups had to wait for a vehicle to pass before they were able to cross. None of the gapcrossing groups had to wait for any passing vehicles. The five groups that had to wait for a yielding vehicle only had to wait for one passing vehicle each before the next vehicle yielded to them. This results in a yield rate of $80.00 \%$. 
A Study of Effectiveness of Midblock Pedestrian Crossings

Apardian, R. and Alam, B. M.

Interdisciplinary Journal of Signage and Wayfinding; Volume 1; Issue 2

Table 5

\section{Data from High-Visibility Midblock Signage Location \#3}

Location: E Rich Street, between High Street and 3rd Street, across from Columbus Commons

Design: Striped, Row of triangles leading up to crosswalk, Diamond-shaped neon pedestrian sign with neon rectangular arrow below on each side of street, White reflective "yield here to pedestrian" square sign each side of street, Overhead diamond-shaped neon pedestrian sign

Street: 3 lanes of one-way western travel, no posted speed limit

\begin{tabular}{|c|c|c|c|}
\hline $\begin{array}{c}\text { Number of Pedestrians } \\
\text { Per Crossing }\end{array}$ & $\begin{array}{c}\text { Type of } \\
\text { Eventual Crossing }\end{array}$ & $\begin{array}{c}\text { Number of Vehicles } \\
\text { Passed Before Crossing }\end{array}$ & Near Conflict \\
\hline 4 & yield & 0 & \\
\hline 1 & yield & 1 & \\
\hline 1 & yield & 0 & \\
\hline 2 & yield & 0 & \\
\hline 3 & yield & 0 & \\
\hline 2 & yield & 0 & \\
\hline 2 & yield & 0 & \\
\hline 3 & yield & 0 & \\
\hline 3 & yield & 0 & \\
\hline 3 & yield & 0 & \\
\hline 1 & yield & 0 & \\
\hline
\end{tabular}


A Study of Effectiveness of Midblock Pedestrian Crossings

Apardian, R. and Alam, B. M.

Interdisciplinary Journal of Signage and Wayfinding; Volume 1; Issue 2

\begin{tabular}{|c|c|c|}
\hline 3 & yield & 1 \\
\hline 1 & yield & 0 \\
\hline 1 & yield & 0 \\
\hline 1 & yield & 0 \\
\hline 1 & yield & 1 \\
\hline 2 & yield & 1 \\
\hline 1 & yield & 0 \\
\hline $3+1$ & yield & 0 \\
\hline 3 & gap & 0 \\
\hline 5 & gap & 0 \\
\hline 4 & yield & 0 \\
\hline 1 & yield & 0 \\
\hline 2 & yield & 0 \\
\hline 1 & yield & 1 \\
\hline 1 & yield & 0 \\
\hline 1 & gap & 0 \\
\hline 2 & gap & 0 \\
\hline 2 & gap & 0 \\
\hline 2 & yield & 0 \\
\hline 1 & yield & 0 \\
\hline 1 & yield & 0 \\
\hline
\end{tabular}


A Study of Effectiveness of Midblock Pedestrian Crossings

Apardian, R. and Alam, B. M.

Interdisciplinary Journal of Signage and Wayfinding; Volume 1; Issue 2

\begin{tabular}{|c|c|c|c|}
\hline $2+1$ & yield & 0 & \\
\hline $1+5$ & yield & 0 & \\
\hline 1 & yield & 0 & \\
\hline 1 & yield & 0 & \\
\hline $5+1+2$ & yield & 0 & \\
\hline $1+1$ & yield & 0 & \\
\hline 1 & yield & 0 & \\
\hline 1 & gap & 0 & \\
\hline 1 & gap & 0 & \\
\hline 6 & gap & 0 & \\
\hline 2 & yield & 0 & \\
\hline 1 & gap & 0 & \\
\hline 2 & yield & 0 & \\
\hline 3 & gap & 0 & \\
\hline 1 & gap & 0 & \\
\hline 1 & gap & 0 & \\
\hline 4 & yield & 0 & \\
\hline 3 & gap & 0 & \\
\hline 1 & gap & 0 & \\
\hline 1 & gap & 0 & \\
\hline 4 & yield & 0 & \\
\hline
\end{tabular}


A Study of Effectiveness of Midblock Pedestrian Crossings

Apardian, R. and Alam, B. M.

Interdisciplinary Journal of Signage and Wayfinding; Volume 1; Issue 2

\begin{tabular}{|c|c|c|c|c|}
\hline 3 & gap & 0 & \\
\cline { 2 - 5 } & 3 & yield & 0 & \\
\cline { 2 - 5 } & 1 & yield & 0 & \\
\cline { 2 - 5 } & 2 & gap & 0 & \\
\cline { 2 - 6 } & 1 & yield & 0 & \\
\cline { 2 - 6 } & $4+5+1+1$ & yield & 0 & \\
\cline { 2 - 6 } & 1 & yield & 0 & \\
\cline { 2 - 6 } & $6+1$ & yield & 0 & \\
\hline Total & 148 & yield & 0 & \\
\hline
\end{tabular}


A Study of Effectiveness of Midblock Pedestrian Crossings Apardian, R. and Alam, B. M.

Interdisciplinary Journal of Signage and Wayfinding; Volume 1; Issue 2

Table 6

Summary of High-Visibility Signage Midblock Crossing Location \#3

\begin{tabular}{|l|c|c|}
\hline Number of Pedestrians That Crossed: \\
\hline During Gap & 37 & $25.00 \%$ \\
\hline During Yield & 111 & $75.00 \%$ \\
\hline Forced Yield & 0 & $0.00 \%$ \\
\hline & 148 & \\
\hline
\end{tabular}

\begin{tabular}{|l|c|l|}
\hline Number of Groups That Crossed: \\
\hline During Gap & 17 & $27.42 \%$ \\
\hline During Yield & 45 & $72.58 \%$ \\
\hline Forced Yield & 0 & \\
\hline & 62 & \\
\hline
\end{tabular}

\begin{tabular}{|l|c|}
\hline Vehicles That Passed & 5 \\
\hline Vehicles That Yielded & 45 \\
\hline
\end{tabular}


A Study of Effectiveness of Midblock Pedestrian Crossings

Apardian, R. and Alam, B. M.

Interdisciplinary Journal of Signage and Wayfinding; Volume 1; Issue 2

\begin{tabular}{|l|c|}
\hline Total Vehicles & 50 \\
\hline Yield Rate & $\mathbf{8 0 . 0 0 \%}$ \\
\hline
\end{tabular}

At this location, drivers were very willing to yield and displayed a high level of visibility. On approximately seven crossings, yielded drivers saw additional pedestrian(s) nearing the crosswalk and decided to wait for them to reach and allowed them time to cross, even after already yielding to a group. This did not occur once at the other crossing locations.

The observations here support the literature's findings that more lanes decrease the chance of yielding. The road on High Street had four travel lanes plus one turn lane, making it a fairly wide street. The three lanes on Rich Street make for a much narrower road and perhaps increase the yield rate. Motorists were also traveling at lower speeds on Rich Street, despite the lack of a posted speed limit. This may have also facilitated a higher yield rate, which would support the literature's findings that lower speeds result in higher yield rates.

This paper also hypothesizes a few more reasons why the location at Rich Street may have found more vehicles willing to yield. First, the overhead signage increases visibility of a crosswalk that all lanes are able to see. The majority of drivers, regardless of travel lane, would likely be able to see the warning signage. This may have a positive impact on yield rate. I would expect to find an increased yield rate if overhead signage was introduced at the locations on High Street. Second, the one-way road creates an environment in which side-mounted signage can be seen by two of the three lanes rather than two of the five lanes as seen on High Street. A warning is useless if it is not visible or obstructed by fellow drivers' cars.

Finally, this paper hypothesizes that driver experiences may impact their likeliness to yield. Groups of same users relate to one another. In the current transportation culture in this city, 
A Study of Effectiveness of Midblock Pedestrian Crossings

Apardian, R. and Alam, B. M.

Interdisciplinary Journal of Signage and Wayfinding; Volume 1; Issue 2

pedestrians (as well as bicyclists and transit riders) are viewed as the less-than group by many drivers. At the Rich Street location, a large majority of pedestrians crossing the street turned into drivers a few minutes later. The parking garage exit fed into the same stream of traffic that crossed the crosswalk. Though not all traffic passing had come from the garage, drivers that had just been pedestrians on that same crosswalk are expected to be more aware of the pedestrian environment they were just a part of and thus more likely to yield, as they were yielded to. Additionally, even if a driver had not just crossed that crosswalk and come from the garage, they are at minimum subconsciously aware that many pedestrians are headed into the garage where they will also become drivers. And finally, the majority of pedestrians crossing at this location were clearly business professionals leaving work for the day, which is what the majority of the crossing drivers were also likely doing. The ability to empathize, even subconsciously, could be a powerful behavior modifier.

Overall, this crossing met the three criteria for "effective." There were no near conflicts, there is high visibility of the pedestrian, and the yield rate is relatively high. Drivers were able to see approaching pedestrians from far away as was observed by their decision to wait for additional pedestrians to cross.

\section{In-Street Signage on Woodruff Avenue}

The final sign study conducted analyzed in-street signage. The location studied was on Woodruff Avenue in the Ohio State University, across from the Physics Research Building (Map 4). The road is a two lane, high pedestrian volume and high-moderate vehicle volume two way street. Pedestrian warning signs include a striped crosswalk with parallel striped lines leading up to crosswalk in each direction, diamond-shaped side-mounted neon pedestrian signs with downward arrows on each side, and an in-street "yield to pedestrian" sign in between the two lanes (Figure 4). The posted speed limit is $20 \mathrm{MPH}$. 
A Study of Effectiveness of Midblock Pedestrian Crossings

Apardian, R. and Alam, B. M.

Interdisciplinary Journal of Signage and Wayfinding; Volume 1; Issue 2

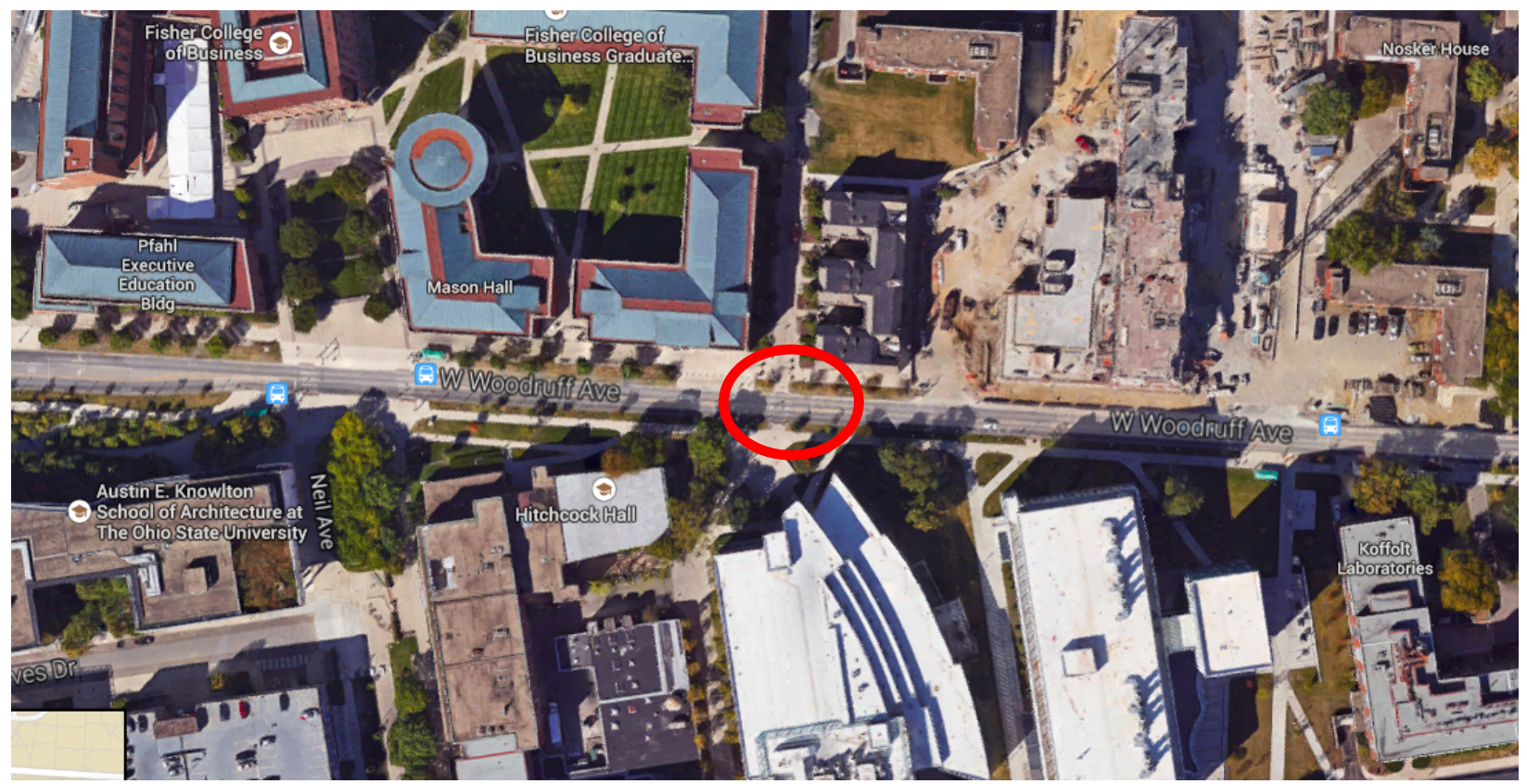

Map 4: Woodruff Avenue in the Ohio State University, across from the Physics Research Building (Google Maps) 
A Study of Effectiveness of Midblock Pedestrian Crossings Apardian, R. and Alam, B. M.

Interdisciplinary Journal of Signage and Wayfinding; Volume 1; Issue 2

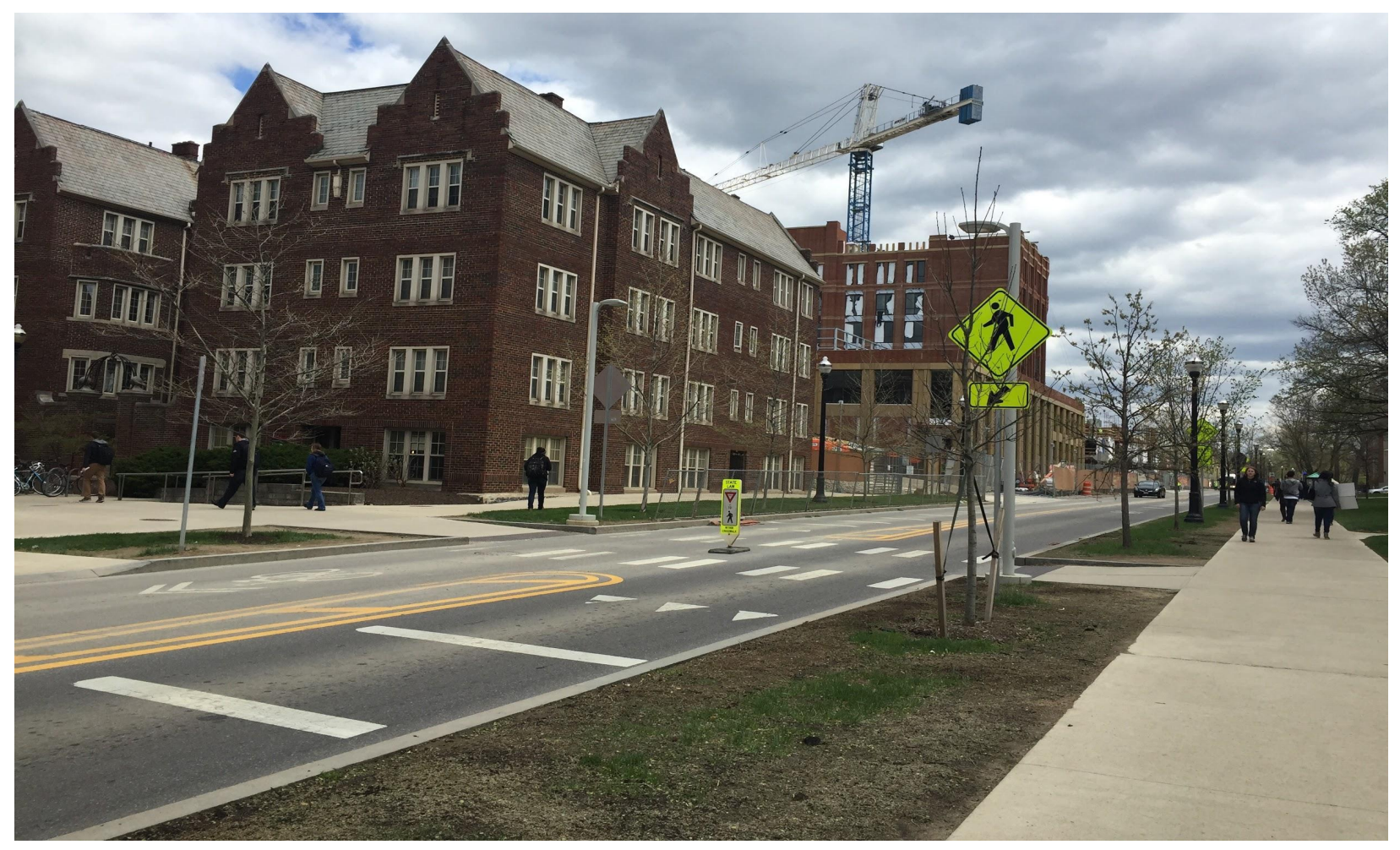

Figure 4: In-street sign crossing conditions on Woodruff Avenue in the Ohio State University, across from the Physics Research Building

Observations at this location can be found in Table 7. There was a total of 253 crossing pedestrians in a total of 52 groups. $12(23.08 \%)$ groups crossed the street during a natural gap in traffic and the remaining 40 groups $(76.92 \%)$ crossed during a yield. This summary can be found in Table 8. There were no near conflicts or forced yields. Pedestrian group sizes ranged from one to 17 , the largest of any location. Often, drivers would wait for additional approaching pedestrians in the same manner that was observed on Rich Street. 
A Study of Effectiveness of Midblock Pedestrian Crossings

Apardian, R. and Alam, B. M.

Interdisciplinary Journal of Signage and Wayfinding; Volume 1; Issue 2

Table 7

\begin{tabular}{|c|c|c|c|}
\hline \multicolumn{4}{|c|}{ Data from In-Street Signage Midblock Crossing Location } \\
\hline \multicolumn{4}{|c|}{ Location: Ohio State University, Woodruff Avenue Across from Physics Research Building } \\
\hline \multicolumn{4}{|c|}{$\begin{array}{l}\text { Design: Striped crosswalk with perpendicular lines leading up to crosswalk in each direction, } \\
\text { Diamond-shaped high-visibility pedestrian signs with arrows, In-street yield to pedestrian } \\
\text { sign }\end{array}$} \\
\hline \multicolumn{4}{|c|}{ Street: 2 lanes in opposite direction, $20 \mathrm{MPH}$} \\
\hline $\begin{array}{c}\text { Number Pedestrians } \\
\text { Per Crossing }\end{array}$ & $\begin{array}{c}\text { Type of } \\
\text { Eventual Crossing }\end{array}$ & $\begin{array}{c}\text { Number Vehicles Passed } \\
\text { Before Crossing }\end{array}$ & $\begin{array}{c}\text { Near } \\
\text { Conflict }\end{array}$ \\
\hline 6 & gap & 0 & \\
\hline 3 & yield & 0 & \\
\hline 1 & gap & 0 & \\
\hline 1 & yield & 0 & \\
\hline 1 & gap & 0 & \\
\hline 3 & gap & 0 & \\
\hline 1 & gap & 0 & \\
\hline 2 & gap & 0 & \\
\hline 1 & gap & 1 & \\
\hline 2 & yield & 0 & \\
\hline 5 & yield & 0 & \\
\hline 2 & yield & 0 & \\
\hline
\end{tabular}


A Study of Effectiveness of Midblock Pedestrian Crossings

Apardian, R. and Alam, B. M.

Interdisciplinary Journal of Signage and Wayfinding; Volume 1; Issue 2

\begin{tabular}{|c|c|c|}
\hline 6 & gap & 0 \\
\hline 4 & gap & 0 \\
\hline 1 & gap & 1 \\
\hline 1 & gap & 0 \\
\hline 8 & yield & 1 \\
\hline 4 & yield & 0 \\
\hline 3 & yield & 0 \\
\hline 3 & yield & 0 \\
\hline 3 & yield & 0 \\
\hline 4 & yield & 0 \\
\hline 3 & yield & 0 \\
\hline 1 & yield & 1 \\
\hline 3 & yield & 0 \\
\hline 10 & yield & 0 \\
\hline 1 & yield & 2 \\
\hline 14 & yield & 0 \\
\hline 3 & yield & 0 \\
\hline 5 & yield & 0 \\
\hline 3 & yield & 0 \\
\hline 5 & yield & 0 \\
\hline 1 & gap & 0 \\
\hline
\end{tabular}


A Study of Effectiveness of Midblock Pedestrian Crossings

Apardian, R. and Alam, B. M.

Interdisciplinary Journal of Signage and Wayfinding; Volume 1; Issue 2

\begin{tabular}{|c|c|c|c|c|}
\hline & 15 & yield & 0 & \\
\hline & 11 & yield & 0 & \\
\hline & 7 & yield & 2 & \\
\hline & 6 & yield & 0 & \\
\hline & 2 & yield & 0 & \\
\hline & 7 & yield & 1 & \\
\hline & 1 & yield & 1 & \\
\hline & 7 & yield & 0 & \\
\hline & 3 & yield & 0 & \\
\hline & 17 & yield & 0 & \\
\hline & 6 & yield & 0 & \\
\hline & 8 & yield & 0 & \\
\hline & 6 & yield & 0 & \\
\hline & 6 & yield & 0 & \\
\hline & 7 & yield & 0 & \\
\hline & 7 & yield & 0 & \\
\hline & 4 & yield & 0 & \\
\hline & 14 & yield & 0 & \\
\hline & 5 & yield & 0 & \\
\hline Total & 253 & & 10 & 0 \\
\hline
\end{tabular}


A Study of Effectiveness of Midblock Pedestrian Crossings Apardian, R. and Alam, B. M.

Interdisciplinary Journal of Signage and Wayfinding; Volume 1; Issue 2

Table 8

Summary of In-Street Signage Midblock Crossing Location

\begin{tabular}{|l|c|c|}
\hline \multicolumn{3}{|l|}{ Number of Pedestrians That Crossed: } \\
\hline During Gap & 28 & $11.07 \%$ \\
\hline During Yield & 225 & $88.93 \%$ \\
\hline Forced Yield & 0 & \\
\hline & 253 & \\
\hline
\end{tabular}

\begin{tabular}{|l|c|c|}
\hline \multicolumn{3}{|l|}{ Number of Groups That Crossed: } \\
\hline During Yield & 40 & $76.92 \%$ \\
\hline During Gap & 12 & $23.08 \%$ \\
\hline Forced Yield & 0 & \\
\hline & 52 & \\
\hline
\end{tabular}

\begin{tabular}{|l|c|}
\hline Vehicles That Passed & 10 \\
\hline Vehicles That Yielded & 40 \\
\hline Total Vehicles & 50 \\
\hline Yield Rate & $\mathbf{8 0 . 0 0 \%}$ \\
\hline
\end{tabular}

The yield rate calculated for this location was $80.00 \%$ (10 vehicles passed waiting pedestrians and 40 yielded to them). This is consistent with the literature findings of an average of $87 \%$ yield rate. Based on observations, I believe yielding rates would have been higher if the pedestrian 
A Study of Effectiveness of Midblock Pedestrian Crossings

Apardian, R. and Alam, B. M.

Interdisciplinary Journal of Signage and Wayfinding; Volume 1; Issue 2

volume was slightly less. Drivers appeared to get frustrated by the large amount of pedestrians crossing and holding them up. For the most part, every vehicle would take its turn yielding to a group of pedestrians, so that almost every other vehicle was yielding. Qualitatively speaking, however, the behavior appeared to indicate that some drivers simply did not want to wait any longer and were then unwilling to yield themselves.

It was a safe crossing environment, however. The in-street signage, combined with narrow lanes, slow speed, and the high visibility of pedestrians waiting caused this crossing to meet the three criteria for "effective:" there were no near conflicts, there is high visibility of the pedestrian, and the yield rate is relatively high.

\section{Conclusions}

In conjunction with the literature, we can see that number of lanes, the width of roadway, and speed matter. The slower streets and the narrower streets saw higher yield percentages, resulting in more effective crossings. Slower speeds and narrow streets facilitate slower vehicle travel, allowing drivers more time to become aware of pedestrians waiting to cross. These higher yield percentages meant that because drivers voluntarily yielded to a waiting pedestrian more often, fewer conflicts occurred and a safer environment was maintained.

As suggested by the literature, in-street signs may prove to be effective, resulting in safe crossing conditions and high yield rates. Another trend in the research done in this paper was that higher pedestrian volumes tended to see higher yield rates. This is consistent with what was observed at the crossings in this study. This is certainly the case here. Comparing the two crossings on High Street with the crossing on Rich Street, we can see a much higher yield rate and much higher pedestrian volume at Rich Street. In addition to higher yield rates, increased pedestrian volumes seemed to produce a safer crossing environment. No groups of more than 2 felt the need to force a yield in any scenario. This could be because a higher pedestrian presence demands more 
A Study of Effectiveness of Midblock Pedestrian Crossings

Apardian, R. and Alam, B. M.

Interdisciplinary Journal of Signage and Wayfinding; Volume 1; Issue 2

attention from a driver and begins to re-prioritize the street's users, causing drivers to feel obligated to yield. Or it could simply result in drivers becoming accustomed to yielding at particular locations, knowing the pedestrian presence is high.

Overhead signage and dual side-mounted signs contributed to a more effective crossing, as evidenced by the high yield percentage at the Rich Street location. The increased visibility of warning signs may benefit pedestrian safety. With overhead signage in particular, nearly all vehicles should have an unobstructed view of the pedestrian warning. This may translate to more drivers taking notice of and obeying the sign, resulting in greater awareness of a pedestrian presence and a greater probability of drivers yielding.

The two High Street locations, just four blocks apart, showed no difference in yield rates, despite the additional signage posted at the 14th Avenue location. At that location, an additional highvisibility arrow sign was posted below the diamond-shaped high-visibility pedestrian sign to indicate to vehicles where a pedestrian would cross. The observations, which were performed on the same day, indicated no discernable difference in either driver awareness or driver yield rate.

Finally, it is expected that driver experiences and their ability to relate to other road users may help influence their behaviors, as was observed as a possibility on Rich Street. It is likely that a driver who had just acted as a pedestrian would be more apt to be aware of and yield to a pedestrian in the near or immediate future, resulting a safer street.

\section{Limitations and Recommendations for Future Work}

This research has shortcomings and limitations which yield to future studies. First, the two High Street locations were quite similar in design and it may be beneficial to observe the same highvisibility signage effectiveness along a roadway with different characteristics to determine where it may be most successful. It is important to determine the impact that each location's individual 
A Study of Effectiveness of Midblock Pedestrian Crossings

Apardian, R. and Alam, B. M.

Interdisciplinary Journal of Signage and Wayfinding; Volume 1; Issue 2

characteristics have on driver yield rate. For example, the same high-visibility signage found at High Street may be more effective along a roadway with fewer lanes, narrower lanes, or a lower speed limit. Differentiating the impact of each roadway element will help determine the most appropriate way to utilize each tool.

It would be advantageous to study another location where overhead warning signage exists, but in an environment without a high pedestrian-to-driver turnover rate. Separating this variable would allow for additional study of overhead signage and its impact on driver yield rates without the additional influence of a recent experience as a pedestrian. Additionally, a separate study analyzing the impact of driver experiences on yielding behavior would be necessary to address this hypothesis. This analysis could differentiate the impact of experience on driver behavior from the impact of signage. For example, a driver who had just recently acted as a crossing pedestrian may be more willing to yield to or more aware of pedestrians crossing in the same place, regardless of available signage. If this is the case, planners could choose to apply this in street designs to improve pedestrian safety.

In future work, I would also like to separate the overhead signage variable from the one-way street variable to see the effects each of these may have on driver yield rate. As Walker, Kulash, and McHugh point out, one-way streets typically give way to a higher vehicle speed and decreased safety for pedestrian users. This is contrary to the environment observed at the Rich Street crossing location, so it would be useful to observe an additional variety of combinations of one-way and two-way streets and high-visibility signage, in-street signs, and overhead options.

Finally, studying the in-street signage in a non-university setting with less pedestrian traffic may be beneficial in understanding the limitation of this method. Though it received a very high yield rate consistent with the literature, a control may be necessary to determine if pedestrian volume or in-street signage had the biggest effect here. 
A Study of Effectiveness of Midblock Pedestrian Crossings Apardian, R. and Alam, B. M.

Interdisciplinary Journal of Signage and Wayfinding; Volume 1; Issue 2

Walking is an important mode of transportation throughout our communities. Pedestrian travel is also increasingly becoming a more convenient and desirable mode of travel as cities work improve walkablility, health, and equity. Midblock crossings must be utilized in order to contribute to this convenience as they encourage pedestrians to cross legally. An important part of ensuring a successful and walkable community is safety. The pedestrian awareness/warning methods studied at midblock crossings in this paper can all be effective elements towards increased safety. These signals, signs, and pavement markings each have environments in which they are most effectively leveraged to alert drivers to pedestrians. Along with narrower road widths, slower speeds, and fewer lanes, these elements can help planners and engineers increase pedestrian crossing safety and install effective midblock crossings. 